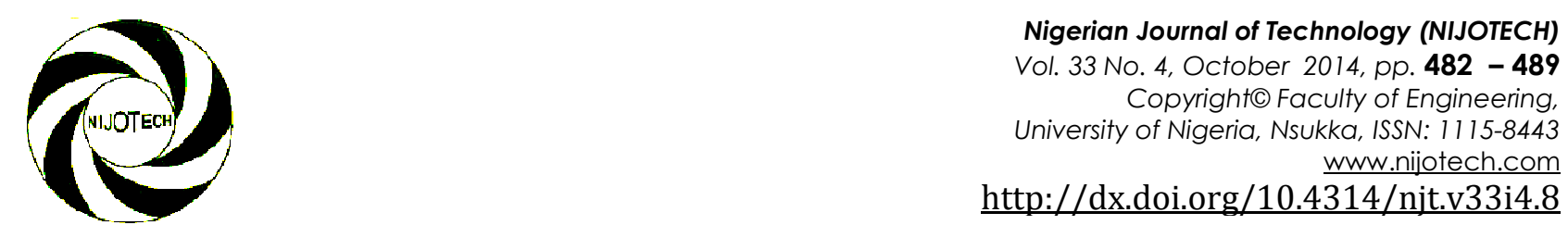

\title{
AN INVESTIGATION OF TIME-COST-RISK TRADE-OFF IN THE INSTALLATION OF X-RAY MACHINE USING RESPONSE SURFACE METHODOLOGY
}

\author{
S.C. Nwaneri ${ }^{1, *}$ and C.0. Anyaeche ${ }^{2}$

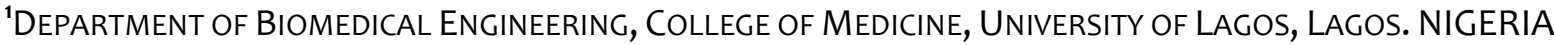 \\ ${ }^{2}$ DEPARTMENT OF INDUSTRIAL AND PRODUCTION ENGINEERING, UNIVERSITY OF IBADAN, IBADAN. NIGERIA \\ E-mail addresses: 1,snwaneri@unilag.edu.ng, 2 osita.anyaeche@ui.edu.ng
}

\begin{abstract}
The conflicting objectives of time, cost and risk are critical to the success of any project. Consequently, an improvement in one objective may lead to a simultaneous degradation of the conflicting objective. Project managers usually desire the minimization of the duration, cost and risk of a project while maximizing project quality. While the Time-Cost trade-off Problem (TCTP) and Time-Cost-Quality trade-off problem (TCQTP) have been well researched not much studies have been done on the Time-Cost-Risk trade-off problem (TCRTP). The objective of this study is to develop an optimization model for TCRTP based on some realistic assumptions with the aim of minimizing time, cost and risks while ensuring that the project is completed based on specifications. Optimization models were developed for the problem and solved using response surface methodology on Minitab 16 statistical software. The model was applied to the installation procedures for X-ray machines.
\end{abstract}

Keywords: Time, cost, risk, project, $x$-ray machines

\section{INTRODUCTION}

Project management as defined by the British standard Institute "'is a unique set of co-ordinated activities, with definite starting and finishing points, undertaken by an individual or organization to meet specific objectives within defined schedule, cost and performance parameters"[1]. Project scheduling is therefore an important aspect of project management. An efficient scheduling system is vital to the overall success of a project. The purpose of project scheduling is to balance the fundamental objectives of a project management which include completion time, total cost and quality while ensuring that the project scope is preserved [2]. Project managers strive to complete projects at minimal duration and cost and at the best quality possible.

In project management, the need to complete the project before schedule may arise due to several reasons. In such cases the duration of the project can be shortened by project crashing. This is usually achieved by the allocation of additional resources in order to speed up the project activities. The allocation of additional resources leads to an increase in the direct costs of the project and is often referred to as the Time-Cost trade-off problem (TCTP) in project management [3][4][5][6][7]. The TCTP assumes a single nonrenewable resource, which is mostly the cost.

The direct costs of the project are activity based costs. They generally increase as the project is crashed.
Examples of direct costs include labour costs, equipment costs, cost of materials etc. On the contrary, indirect costs generally decrease as the duration of the project is reduced. Costs such as overhead costs, security costs, insurance all fall within this category. While this problem is very common in the construction industry, where projects might be required to be completed before the actual duration, it is also applicable in other industries such as software development, communications projects, power generation projects, etc.

The TCTP has been studied under different assumptions for the cost function. These include discrete [8], linear-continuous [9], linear-piecewise [10], non-linear convex [11], mixed (continuous and discrete) [12] cost functions. In the discrete version of the problem, the relation among the time and cost are defined as discrete functions. This means that for each project activity, different modes of execution are available and for each mode a different time and cost is possible. On the contrary, for the continuous version, the relation among the time, cost and quality is defined by continuous functions. The TCTP was proved by [5] to be strongly NP-hard. NP-hard problems are decision problems in combinatorial optimization for which no polynomial time algorithms are known. As a result, it is not possible to obtain optimal solutions for large projects using analytical method as this has proved to be prohibitively timeconsuming. 
Mathematical and heuristic methods are the two main approaches used to solve time-cost trade-off problems in project scheduling. When using mathematical methods, the problem is first converted to mathematical models and solved using mathematical programming techniques. The advantages of mathematical approaches include efficiency and accuracy [13]. The main problem with mathematical approaches is that they can be time consuming and may have difficulty solving NP-hard problem. However, meta-heuristic algorithms provide good solutions in reasonable time and can be efficient for large projects. Therefore there are different methods for solving a problem with more than one objective. The methods include considering a new objective defined by weighted sum of the multiple objectives, bounding all but one of the objectives and trying to optimize the selected one and find the Pareto optimal solution set. A solution is Pareto optimal, if there is no feasible solution, for which an improvement in one objective does not lead to a simultaneous reduction in performance of one or more of the remaining objectives [14].

The time, cost, quality and risks are important objectives in the management of a project. The project manager should ensure that projects are executed within the specified duration and budget and quality. Every project is characterized by various degrees of risk. The concept of risk is more pronounced in some projects than others. Project crashing leads to an increase in resource utilization which eventually leads to increased construction cost for the project and vice versa. In addition to time and cost of activities, each resource utilization option will yield specific risks [15]. The trade-off between these conflicting objectives of a project known as the Time-Cost-Risk trade-off problem (TCRTP) is a challenging task which has not been fully addressed in the literature.

In recent times, the safety of project participants has become an issue of critical concern. This is probably due to the high costs associated with employee compensation and criminal prosecutions as a result of unsafe working environment [16]. Also, project contracts are usually given to contractors or consultants with a record of safe projects delivery. [17] point out that safety improvement measure is an approach towards reassuring customers, thereby improving their satisfaction. Though several researchers have identified accident investigations or causes, and risk management as an approach towards addressing and improving safety issues in the work/ project environment [18][19][20], little research has been done on how safety impacts on time-cost tradeoff problem. The objective of this study is to develop a model suitable for addressing the Time-Cost-Risk trade-off problem. The model will be applied to a project for the installation of X-ray machine. The study will also investigate the health effects associated with exposure to X-rays.

\section{OCCUPATIONAL HAZARDS OF X-RAY MACHINES}

Exposure to diagnostic X-rays increase the risk of developmental problems and cancer in those exposed [21]. The World Health Organization's International Agency for Research on Cancer classify X-rays as carcinogen [22].There is a high possibility a person's cumulative risk of getting cancer by age 75 by $0.6-$ $1.8 \%$.will be increased by additional radiation. The amount of absorbed radiation depends upon the type of X-ray test and the body part involved. CT and fluoroscopy entail higher doses of radiation than do plain X-rays [23].Several health risks are associated with the occupational exposure to X-ray radiation which may lead to biological damage. Exposure to Xray is associated with a number of health effects including diseases such as leukemia or bone, breast, lung cancer and even death. Radiation exposure no matter how small is associated with some degree of risk. Radiation workers should therefore ensure that they are not exposed beyond the required dose limits. In addition, the principle of as low as reasonably achievable is applied in order to minimize risks associated with exposure to X-rays [24] (Tufts University, n.d.). X-ray machine installation projects are associated with several risks including radiation leakages, electric shock, trauma, equipment damage due to improper installation.

\section{METHOD OF STUDY}

\subsection{The Mathematical Model}

The problem is to develop an optimization model that can minimize the duration, costs and health risks associated with exposure to X-rays. The model was developed based on the following assumptions:

(1) The risk was quantified using mental estimation of the probability and impact matrix based on the experience of the Engineers.

(2) The normal and crash costs for each activity were assumed to be the lower and upper bounds of the desirable interval of the resources since it is desirable that resources usage is within acceptable limits between normal and crash costs.

(3) The three objectives of time, cost and risk were integrated into the amount of allocated resources to the activities as suggested by [26] for the sake of simplicity.

Before formulating the models, the notations and variables for the problem are stated as follows:

\subsection{Notations and variables}

i Index of activities

$\mathrm{j}$ Index of nodes in project network

A Set of activities

$V$ Set of nodes

$\mathrm{A}_{\mathrm{ij}}$ Activity (i, j) 
$\mathrm{x}_{\mathrm{ij}}$ Mean amount of resource allocated to activity $\mathrm{A}_{\mathrm{ij}}$ $\mathrm{t}_{\mathrm{ij}}\left(\mathrm{x}_{\mathrm{ij}}\right)$ Expected duration of activity when resource $\mathrm{r}_{\mathrm{ij}}$ is assigned to activity $A_{i j}$

$\mathrm{c}_{\mathrm{ij}}\left(\mathrm{x}_{\mathrm{ij}}\right)$ cost of assigning resource $\mathrm{r}_{\mathrm{ij}}$ to activity $\mathrm{A}_{\mathrm{ij}}$

$\mathrm{q}_{\mathrm{ij}}\left(\mathrm{x}_{\mathrm{ij}}\right)$ Expected quality of activity $\mathrm{A}_{\mathrm{ij}}$ when resource $\mathrm{r}_{\mathrm{ij}}$ is assigned to activity $\mathrm{A}_{\mathrm{ij}}$

$\mathrm{u}_{\mathrm{ij}}$ Upper bound of $\mathrm{x}_{\mathrm{ij}}$

$\mathrm{l}_{\mathrm{ij}}$ Lower bound of $\mathrm{x}_{\mathrm{ij}}$

$\mathrm{p}_{\mathrm{ij}}$ Set of all predecessors of activity $(\mathrm{i}, \mathrm{j})$

$S_{i}$ Occurrence time of node $\mathrm{j} \in \mathrm{V}$

C Unit cost of resource

$Q_{\text {min }}$ Total expected quality of project

$\mathrm{R}_{\mathrm{ij}}$ Total value of risk for project activities

A mathematical formulation of the problem is as follows:

$$
\begin{aligned}
& \text { Min } \mathrm{f}_{1}=\sum_{(\mathrm{i}, \mathrm{j}) \in \mathrm{B}} \mathrm{t}_{\mathrm{ij}}\left(\mathrm{x}_{\mathrm{ij}}\right) \\
& \operatorname{Min} \mathrm{f}_{2}=\sum_{(\mathrm{i}, \mathrm{j}) \in \mathrm{A}} \mathrm{c}_{\mathrm{ij}}\left(\mathrm{x}_{\mathrm{ij}}\right) \\
& \operatorname{Min} \mathrm{f}_{3}=\sum_{(\mathrm{i}, \mathrm{j}) \in \mathrm{A}} \mathrm{R}_{\mathrm{ij}}\left(\mathrm{x}_{\mathrm{ij}}\right)
\end{aligned}
$$

Subject to:

$\begin{array}{lc}S_{j}-S_{i} \geq t_{i j}\left(x_{i j}\right) & \text { for all }(i, j) \in A \\ l_{i j} \leq x_{i j} \leq u_{i j} & \text { for all }(i, j) \in A \\ S_{1}=0, & i j \in V \quad(i, j) \in A \\ R \geq 0 & t_{i j}\left(x_{i j}\right) \geq 0 \quad S_{i} \geq 0,\end{array}$

\subsection{Model Description}

The above objectives are consistent with those used by other researchers in related studies [2] [3] [4] [5] [6] [7] [26].The explanation given for the above equations is as follows.

\subsubsection{Objective Functions}

1. Equation (1) describes the objective function $f_{1}$ which minimizes the total expected completion time.

2. Equation (2) minimizes the expected resource consumption cost,

3. Equation (3) minimizes the project risk.

\subsubsection{Constraints}

1. Equation (4) is the precedence constraint that guarantees that the precedence relations between project activities are preserved.

2. Equation (5) ensures that the limits of resources allocated to the activities are not violated.

3. Equation (6) shows the starting time of project to be zero,

4. Equation(7) shows the non-negativity constraints.

Risk is a difficult value to measure and the ability to apply risk management tools remains one of the most difficult problems facing management in most organizations [28].The effectiveness of decision makers risk attitude index for fuzzy critical path analysis was considered by [29].The risk values were calculated using the method proposed by [30]. This is computed as the product of the probability of risk occurrence and its impact given by:

$\mathrm{R}=\mathrm{P} * \mathrm{I}$

Where $\mathrm{R}$ is the risk index, $\mathrm{P}$ the probability of occurrence and I the risk impact.

The probability and impact of the risks involved in the different project activities were estimated based on the experience of the engineers involved and computed using the probability impact matrix.

\subsection{Application of the Model}

The solution method was applied to a typical installation procedure for a static X-ray machine GE silhouette XR 6000.The work breakdown structure for the $\mathrm{x}$-ray machine installation project is shown in Table 2 .

Table 1: Probability-Impact Matrix

\begin{tabular}{cccccc}
\hline & \multicolumn{5}{c}{ IMPACT } \\
\cline { 2 - 6 } PROBABILITY & $\begin{array}{c}\text { Extremely } \\
\text { Low } \\
\text { Impact } \\
(0.1)\end{array}$ & $\begin{array}{c}\text { Low Impact } \\
(0.2)\end{array}$ & $\begin{array}{c}\text { Moderate } \\
\text { Impact } \\
(0.5)\end{array}$ & $\begin{array}{c}\text { High } \\
\text { impact } \\
(0.8)\end{array}$ & $\begin{array}{c}\text { Extremely High } \\
\text { Impact } \\
(1)\end{array}$ \\
\hline Certain(1) & 0.10 & 0.20 & 0.50 & 0.80 & 1.00 \\
Very Likely(0.8) & 0.08 & 0.16 & 0.40 & 0.64 & 0.80 \\
Possible(0.5) & 0.05 & 0.10 & 0.25 & 0.40 & 0.50 \\
Unlikely(0.2) & 0.02 & 0.04 & 0.10 & 0.16 & 0.20 \\
Rare(0.1) & 0.01 & 0.02 & 0.05 & 0.08 & 0.10 \\
\hline
\end{tabular}

Table 2: Work package for the $X$-ray machine installation project

\begin{tabular}{cccccccc}
\hline $\begin{array}{c}\text { Work } \\
\text { package }\end{array}$ & Description & $\begin{array}{c}\text { Immediate } \\
\text { Predecessor }\end{array}$ & $\begin{array}{c}\mathrm{t}_{\mathrm{ij}} \\
(\text { days })\end{array}$ & $\begin{array}{c}\mathrm{t}_{\mathrm{ij}} \\
(\mathrm{days})\end{array}$ & $\begin{array}{c}\mathrm{C}_{\mathrm{ij}} \\
(\mathrm{N} 1,000)\end{array}$ & $\begin{array}{c}\mathrm{C}_{\mathrm{ij}}^{\prime} \\
(\mathrm{N} 1,000)\end{array}$ & $\begin{array}{c}\mathrm{R}(\%)= \\
\mathrm{P} \times \mathrm{I}\end{array}$ \\
\hline A & Feasibility studies & - & 5 & 3 & 100 & 120 & 20 \\
$\mathrm{~B}$ & Procurement & $\mathrm{A}$ & 8 & 5 & 800 & 1,000 & 28 \\
$\mathrm{C}$ & Site Selection & $\mathrm{A}$ & 3 & 2 & 200 & 250.00 & 30 \\
$\mathrm{D}$ & Construction Design & $\mathrm{C}$ & 5 & 3 & 120 & 180.00 & 18
\end{tabular}




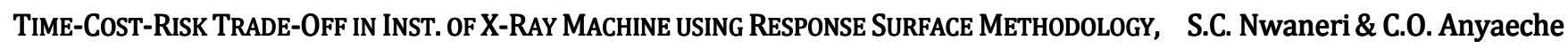

\begin{tabular}{|c|c|c|c|c|c|c|c|}
\hline $\begin{array}{c}\text { Work } \\
\text { package }\end{array}$ & Description & $\begin{array}{c}\text { Immediate } \\
\text { Predecessor }\end{array}$ & $\begin{array}{c}\mathrm{t}_{\mathrm{ij}} \\
\text { (days) }\end{array}$ & $\begin{array}{c}\mathrm{t}_{\mathrm{ij}} \\
\text { (days) }\end{array}$ & $\begin{array}{c}\mathrm{C}_{\mathrm{ij}} \\
(\mathrm{N} 1,000)\end{array}$ & $\begin{array}{c}\mathrm{C}_{\mathrm{ij}}^{\prime} \\
(\mathrm{N} 1,000)\end{array}$ & $\begin{array}{c}\mathrm{R}(\%)= \\
\mathrm{P} \times \mathrm{I}\end{array}$ \\
\hline $\mathrm{E}$ & Construction & $\mathrm{D}$ & 15 & 10 & 230 & 280.00 & 45 \\
\hline $\mathrm{F}$ & $\begin{array}{l}\text { Installation of } \\
\text { radiation barriers }\end{array}$ & $\mathrm{D}$ & 5 & 2 & 160 & 300.00 & 40 \\
\hline G & $\begin{array}{l}\text { Setting up the X-ray } \\
\text { Darkroom }\end{array}$ & $\mathrm{F}$ & 4 & 2 & 100 & 140.00 & 37 \\
\hline $\mathrm{H}$ & $\begin{array}{l}\text { Equipment } \\
\text { Installation }\end{array}$ & $\mathrm{E}$ & 3 & 2 & 150 & 165.00 & 46 \\
\hline I & Calibration & $\mathrm{G}, \mathrm{H}$ & 3 & 2 & 80 & 120.00 & 28 \\
\hline $\mathrm{J}$ & Collimation & I & 4 & 2 & 50 & 60.00 & 32 \\
\hline K & $\begin{array}{l}\text { Tube Warm up } \\
\text { procedure }\end{array}$ & $\mathrm{J}$ & 2 & 1 & 40 & 60.00 & 45 \\
\hline $\mathrm{L}$ & Rotor Activation & K & 3 & 2 & 45 & 54.00 & 35 \\
\hline M & $\begin{array}{c}\text { Final Testing \& } \\
\text { Closure }\end{array}$ & $\mathrm{L}$ & 2 & 1 & 40 & 55.00 & 42 \\
\hline Total & & & & & 2,115 & 2,614 & \\
\hline
\end{tabular}

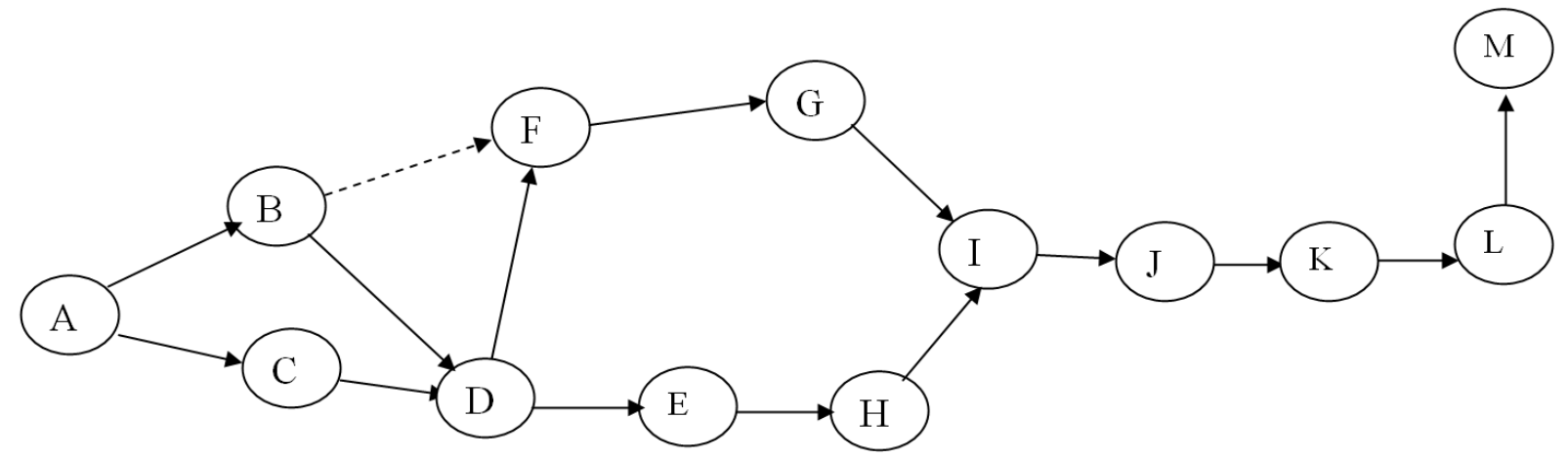

Figure 1: Network Diagram of X-Ray Machine Installation Project

$\underline{\text { Paths }}$

Path1

$\mathrm{t}_{\mathrm{ij}}=\mathrm{A}-\mathrm{B}-\mathrm{D}-\mathrm{F}-\mathrm{G}-\mathrm{I}-\mathrm{J}-\mathrm{K}-\mathrm{L}-\mathrm{M}=41$

$\mathrm{t}^{\prime}{ }_{\mathrm{ij}}=\mathrm{A}-\mathrm{B}-\mathrm{D}-\mathrm{F}-\mathrm{G}-\mathrm{I}-\mathrm{J}-\mathrm{K}-\mathrm{L}-\mathrm{M}=23$

Path 2

$\mathrm{t}_{\mathrm{ij}}=\mathrm{A}-\mathrm{C}-\mathrm{D}-\mathrm{E}-\mathrm{H}-\mathrm{I}-\mathrm{J}-\mathrm{K}-\mathrm{L}-\mathrm{M}=42$

$\mathrm{t}_{\mathrm{ij}}^{\prime}=\mathrm{A}-\mathrm{C}-\mathrm{D}-\mathrm{E}-\mathrm{H}-\mathrm{I}-\mathrm{J}-\mathrm{K}-\mathrm{L}-\mathrm{M}=28$

Path 3

$\mathrm{t}_{\mathrm{ij}}=\mathrm{A}-\mathrm{B}-\mathrm{F}-\mathrm{G}-\mathrm{I}-\mathrm{J}-\mathrm{K}-\mathrm{L}-\mathrm{M}=36$

$\mathrm{t}^{\prime}{ }_{\mathrm{ij}}=\mathrm{A}-\mathrm{B}-\mathrm{F}-\mathrm{G}-\mathrm{I}-\mathrm{J}-\mathrm{K}-\mathrm{L}-\mathrm{M}=20$

The Critical Path = A-C-D-E-H-I-J-K-L-M:

$\mathrm{t}_{\mathrm{ij}}=42$

$\mathrm{t}^{\prime}{ }_{\mathrm{ij}}=28$

$\mathrm{C}_{\mathrm{ij}}=2,115,000.00$

$\mathrm{C}_{\mathrm{ij}}^{\prime}=2,614,000.00$

$\mathrm{R}=0.3431$

\subsection{Experimental Design and Procedure}

In this study, the method proposed by [25] and applied by [26] to the TCQTP was adopted. Essentially, data collection was done to establish the relationship between the objective functions and the decision variables. The design of experiment (DOE) is the approach used for data collection. The main advantage of the technique is its ability to simultaneously determine the individual and interactive effects of altering the various factors that could affect the various outputs of the design. The fractional factorial design of experiment (DOE) was the approach adopted in the collection of data to fit the required model. This method was chosen based on its ability to reduce the number of experimental runs performed to a fraction of a full factorial design while making use of the most important data [27]. The experiment consists of 16 runs, coded as +1 and -1 respectively.

The approximate response surface model is then computed by the equation:

$\mathrm{y}_{\mathrm{j}}=\mathrm{f}_{\mathrm{j}}(\mathrm{x})+\varepsilon \quad \mathrm{j}=1,2$.

Where $f_{j}(x)$ indicates a function between $j^{\text {th }}$ objective and decision variables, and $\varepsilon_{j}$ represents the error observed in the objective $y_{j}$.ere $y_{j}$ is the $j^{\text {th }}$ objective, $f_{j}$ (x) indicates a function between $\mathrm{j}^{\text {th }}$ objective and decision variables, and $\varepsilon_{j}$ represents the error observed in the objective $\mathrm{y}_{\mathrm{j}}$.

First, a specification region was considered consisting of lower and upper limits of resources allocated to each activity as shown in Table 2 . The probability that all objectives simultaneously meet their respective desirable intervals is given by equation (10) below:

$\mathrm{P}(\mathrm{Y} \in \mathrm{S})$

Where $Y$ is a vector of multiple resources and $S$ is the specification region. The lower and upper resource limits are the desirable intervals for the objectives. The normal and crash costs for each activity were assumed to be the lower and upper bounds respectively. 
Table 3: Characteristics of the problem

\begin{tabular}{ccc}
\hline Activity no & $\begin{array}{c}\text { RESOURCE } \\
\text { Lower (N1,000) }\end{array}$ & $\begin{array}{c}\text { LIMITS(N1,000) } \\
\text { Upper bound }\end{array}$ \\
\hline A & 100 & 120 \\
B & 800 & 1000 \\
C & 200 & 250 \\
D & 120 & 180 \\
E & 230 & 280 \\
F & 160 & 300 \\
G & 100 & 140 \\
H & 150 & 165 \\
I & 80 & 120 \\
J & 50 & 60 \\
K & 40 & 60 \\
L & 45 & 54 \\
M & 40 & 55 \\
\hline
\end{tabular}

It was assumed that $\mathrm{Y}$ follows an $m$ dimensional multivariate normal distribution. The mean $\mu$, and variances $\sigma^{2}$ were obtained and used to compute the variance-covariance matrices given in Table 6 below.
Desirable intervals for the different objectives of time, cost and risk are shown in Table 5. Probability values were computed to determine the extent to which the objectives meet the desired interval. The desirable interval for project objectives is given in Table 5 .

Table 6 shows the variance-covariance matrix for each run of experiments as well as the probability of being within the desirable interval for the different trade-off problems. The probability values are reliability indicators with values between 0 and 1 where 0 means total failure to meet desirable interval and 1 total success in meeting the desirable interval [31].The probability of a joint event is often obtained from the probability of individual events [32].Furthermore, the conditional probability for the different trade-offs are computed as shown in $(11-14)$ :

$\mathrm{P}(\mathrm{T} \mathrm{C}$ and $\mathrm{R})=\mathrm{P}(\mathrm{T}) \mathrm{P}(\mathrm{C} \mid \mathrm{T}) \mathrm{P}(\mathrm{R} \mid \mathrm{T}$ and $\mathrm{C})$

$\mathrm{P}(\mathrm{T}$ and $\mathrm{C})=\mathrm{P}(\mathrm{T}) \mathrm{P}(\mathrm{C} \mid \mathrm{T})$

$\mathrm{P}(\mathrm{T}$ and $\mathrm{R})=\mathrm{P}(\mathrm{T}) \mathrm{P}(\mathrm{R} \mid \mathrm{T})$

$\mathrm{P}(\mathrm{C}$ and $\mathrm{R})=\mathrm{P}(\mathrm{C}) \mathrm{P}(\mathrm{R} \mid \mathrm{C})$

Table 4: Experimental Data

\begin{tabular}{cccccccccccccccccccc}
\hline Run & $\mathrm{x}_{1}$ & $\mathrm{x}_{2}$ & $\mathrm{x}_{3}$ & $\mathrm{x}_{4}$ & $\mathrm{x}_{5}$ & $\mathrm{x}_{6}$ & $\mathrm{x}_{7}$ & $\mathrm{x}_{8}$ & $\mathrm{x}_{9}$ & $\mathrm{x}_{10}$ & $\mathrm{t}_{1}$ & $\mathrm{t}_{2}$ & $\mathrm{t}_{3}$ & $\mathrm{c}_{1}$ & $\mathrm{c}_{2}$ & $\mathrm{c}_{3}$ & $\mathrm{R}_{1}$ & $\mathrm{R}_{2}$ & $\mathrm{R}_{3}$ \\
\hline 1 & -1 & -1 & -1 & -1 & -1 & -1 & -1 & -1 & 1 & 1 & 3 & 2.8 & 3.2 & 193 & 230 & 238 & 30 & 28 & 31 \\
2 & 1 & -1 & 1 & -1 & -1 & 1 & -1 & 1 & 1 & -1 & 4.4 & 3.6 & 4.8 & 130 & 128 & 142 & 30 & 32 & 29 \\
3 & -1 & 1 & -1 & -1 & 1 & 1 & -1 & 1 & -1 & -1 & 2.7 & 3.0 & 2.2 & 120 & 132 & 125 & 28 & 31 & 32 \\
4 & 1 & -1 & 1 & 1 & -1 & -1 & 1 & -1 & -1 & -1 & 5.5 & 4.2 & 6.0 & 122 & 145 & 156 & 32 & 33 & 30 \\
5 & -1 & 1 & -1 & 1 & 1 & -1 & 1 & -1 & 1 & -1 & 3.1 & 3.9 & 4.6 & 128 & 131 & 130 & 35 & 29 & 34 \\
6 & 1 & 1 & 1 & -1 & 1 & -1 & -1 & -1 & -1 & 1 & 6.0 & 4.2 & 5.2 & 148 & 153 & 157 & 35 & 32 & 35 \\
7 & 1 & 1 & 1 & 1 & 1 & 1 & 1 & 1 & 1 & 1 & 2.8 & 3.3 & 4.4 & 167 & 172 & 173 & 33 & 31 & 34 \\
8 & -1 & -1 & 1 & 1 & 1 & -1 & -1 & 1 & 1 & 1 & 3.6 & 3.8 & 4.5 & 156 & 158 & 162 & 31 & 30 & 29 \\
9 & 1 & -1 & -1 & 1 & 1 & 1 & -1 & -1 & 1 & -1 & 3.1 & 2.6 & 3.4 & 100 & 105 & 112 & 34 & 32 & 30 \\
10 & 1 & 1 & -1 & 1 & -1 & -1 & -1 & 1 & -1 & 1 & 2.7 & 3.7 & 4.8 & 128 & 131 & 130 & 29 & 29 & 31 \\
11 & 1 & 1 & -1 & -1 & -1 & 1 & 1 & -1 & 1 & 1 & 4.7 & 5.2 & 3.9 & 89 & 93 & 98 & 30 & 32 & 32 \\
12 & -1 & 1 & 1 & 1 & -1 & -1 & 1 & 1 & 1 & -1 & 2.3 & 2.7 & 2.5 & 98 & 94 & 99 & 31 & 30 & 29 \\
13 & -1 & -1 & 1 & -1 & 1 & 1 & 1 & -1 & -1 & 1 & 3.2 & 3.4 & 3.9 & 126 & 123 & 127 & 34 & 36 & 33 \\
14 & -1 & -1 & -1 & 1 & -1 & 1 & 1 & 1 & -1 & 1 & 2.7 & 2.4 & 3.2 & 232 & 234 & 239 & 32 & 34 & 33 \\
15 & 1 & -1 & -1 & -1 & 1 & -1 & 1 & 1 & -1 & -1 & 4.8 & 4.2 & 5.4 & 245 & 252 & 260 & 34 & 34 & 35 \\
16 & -1 & 1 & 1 & 1 & -1 & 1 & -1 & -1 & -1 & -1 & 3.0 & 3.8 & 4.1 & 132 & 127 & 129 & 30 & 31 & 30 \\
\hline
\end{tabular}

Table 5: Desirable interval

\begin{tabular}{lllll}
\hline S/N & PROBLEM & TIME & COST & RISK $(\%)$ \\
\hline 1 & TCRTP & $3<\mathrm{T}<5$ & $80<\mathrm{C}<250$ & $30<\mathrm{R}<50$ \\
2 & TCTP & $3<\mathrm{T}<5$ & $80<\mathrm{C}<250$ & $30<\mathrm{R}<50$ \\
3. & CRTP & $3<\mathrm{T}<5$ & $80<\mathrm{C}<180$ & $30<\mathrm{R}<50$ \\
4 & TRTP & $3<\mathrm{T}<5$ & $80<\mathrm{C}<180$ & $30<\mathrm{R}<50$ \\
\hline
\end{tabular}

Table 6: Table showing Variance-Covariance matrix

\begin{tabular}{|c|c|c|c|c|c|c|c|}
\hline $\mathrm{S} / \mathrm{N}$ & VARIANCE-C & COVARIANC & E MATRIX & $\begin{array}{l}\text { PROBABILITY } \\
\text { FOR TCTP }\end{array}$ & $\begin{array}{c}\text { PROBABILITY } \\
\text { FOR TRTP }\end{array}$ & $\begin{array}{c}\text { PROBABILITY } \\
\text { FOR CRTP }\end{array}$ & $\begin{array}{c}\text { PROBABILITY } \\
\text { FOR TCRTP }\end{array}$ \\
\hline 1 & $\begin{array}{c}0.0400 \\
-0.8000 \\
0.2000\end{array}$ & $\begin{array}{c}-0.800 \\
36.33 \\
-6.1111\end{array}$ & $\begin{array}{c}0.2000 \\
-6.1111 \\
2.333\end{array}$ & 0.3000 & 0.6667 & 0.2222 & 0.3000 \\
\hline
\end{tabular}




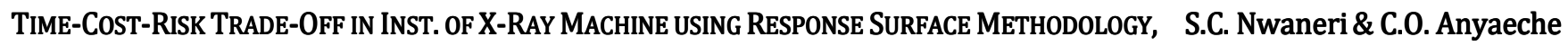

\begin{tabular}{|c|c|c|c|c|c|c|c|}
\hline \multirow{4}{*}{$\frac{\mathrm{S} / \mathrm{N}}{2}$} & \multicolumn{3}{|c|}{ VARIANCE-COVARIANCE MATRIX } & \multirow[t]{2}{*}{$\begin{array}{l}\text { PROBABILITY } \\
\text { FOR TCTP }\end{array}$} & $\begin{array}{c}\text { PROBABILITY } \\
\text { FOR TRTP }\end{array}$ & $\begin{array}{l}\text { PROBABILITY } \\
\text { FOR CRTP }\end{array}$ & $\begin{array}{c}\text { PROBABILITY } \\
\text { FOR TCRTP }\end{array}$ \\
\hline & 0.3733 & -1.8667 & 0.0889 & & & & \\
\hline & -1.8667 & 84.0 & 7.3333 & 1.0000 & 0.6667 & 0.6667 & 0.6667 \\
\hline & 0.0889 & 7.3333 & 1.5556 & & & & \\
\hline \multirow{3}{*}{3} & 0.1633 & 0.5222 & 0.0999 & & & & \\
\hline & 0.52222 & 36.3333 & 4.0000 & 0.3333 & 0.3333 & 1.0000 & 0.3333 \\
\hline & 0.09999 & 4.0000 & 1.0000 & & & & \\
\hline \multirow{3}{*}{4} & 0.8633 & -0.0111 & 0.2667 & & & & \\
\hline & -0.0111 & 4.3333 & -2.333 & 0.3333 & 0.3333 & 1.0000 & 0.3333 \\
\hline & 0.2667 & -2.333 & 3.0000 & & & & \\
\hline \multirow{3}{*}{5} & 0.5633 & 0.5222 & 0.2111 & & & & \\
\hline & 0.52222 & 2.333 & -1.2222 & 1.0000 & 0.0000 & 0.0000 & 0.0000 \\
\hline & 0.2111 & -1.2222 & 4.3333 & & & & \\
\hline \multirow{3}{*}{6} & 0.8133 & -1.3556 & -0.8000 & & & & \\
\hline & -1.3556 & 20.3333 & 9.0000 & 0.2222 & 0.3333 & 0.6667 & 0.2222 \\
\hline & -0.8000 & 9.0000 & 9.0000 & & & & \\
\hline \multirow{3}{*}{7} & 0.6700 & 1.4667 & 0.3667 & & & & \\
\hline & 1.4667 & 10.3333 & 0.3333 & 0.6667 & 0.6667 & 1.0000 & 0.6667 \\
\hline & 0.3667 & 0.3333 & 1.0 & & & & \\
\hline \multirow{3}{*}{8} & 0.2233 & 0.9556 & -0.7222 & & & & \\
\hline & 0.9556 & 9.3333 & -4.889 & 1.0000 & 1.0000 & 1.0000 & 1.0000 \\
\hline & -0.7222 & -4.889 & 6.3333 & & & & \\
\hline \multirow{3}{*}{9} & 0.1089 & 0.7444 & -0.1222 & & & & \\
\hline & 0.7444 & 24.222 & -2.1111 & 0.6667 & 0.6667 & 1.0000 & 0.6667 \\
\hline & -0.1222 & -2.1111 & 0.2222 & & & & \\
\hline \multirow{3}{*}{10} & 0.7356 & 0.6778 & -0.3778 & & & & \\
\hline & 0.6778 & 1.5556 & 0.7778 & 0.6667 & 0.6667 & 1.0000 & 0.6667 \\
\hline & -0.3778 & 0.7778 & 1.5556 & & & & \\
\hline \multirow{3}{*}{11} & 0.2867 & -1.3000 & 0.8667 & & & & \\
\hline & -1.3000 & 13.5556 & -3.3333 & 0.6667 & 0.6667 & 1.0000 & 0.6667 \\
\hline & 0.8667 & -3.3333 & 2.6667 & & & & \\
\hline \multirow{3}{*}{12} & 0.0267 & -0.2667 & 0 & & & & \\
\hline & -0.2667 & 2.8889 & 2.000 & 0.0000 & 0.0000 & 1.0000 & 0.0000 \\
\hline & 0 & 2.0000 & 2.0000 & & & & \\
\hline \multirow{3}{*}{13} & 0.0867 & 0.2333 & -0.0333 & & & & \\
\hline & 0.2333 & 2.8889 & 1.7778 & 1.0000 & 1.0000 & 1.0000 & 1.0000 \\
\hline & -0.0333 & 1.7778 & 1.5556 & & & & \\
\hline \multirow{3}{*}{14} & 0.1089 & 0.7667 & 0.9222 & & & & \\
\hline & 0.7667 & 8.6667 & 5.3333 & 0.0000 & 0.3333 & 0.0000 & 0.0000 \\
\hline & 0.9222 & 5.3333 & 8.2222 & & & & \\
\hline \multirow{4}{*}{15} & 0.2400 & 1.6000 & 0.4000 & & & & \\
\hline & 1.6000 & 37.5556 & 5.1111 & 0.0000 & 1.0000 & 0.0000 & 0.0000 \\
\hline & 0.4000 & 5.1111 & 0.8889 & & & & \\
\hline & 0.2156 & -0.7444 & -0.8889 & & & & \\
\hline \multirow[t]{2}{*}{16} & -0.7444 & 4.2222 & 2.1111 & 1.0000 & 1.0000 & 1.0000 & 1.0000 \\
\hline & -0.8889 & 2.1111 & 4.2222 & & & & \\
\hline
\end{tabular}

Furthermore, the regression equations for the probability of being within the desirable interval were computed using Minitab 16 statistical software as follows:

$\mathrm{P}_{\text {TCTP }}=\mathrm{p}(3<\mathrm{T}<5,50<\mathrm{C}<150,30<\mathrm{R}<50)$

$=0.539-0.011 \mathrm{x}_{1}+0.020 \mathrm{x}_{2}+0.102 \mathrm{x}_{3}+0.116 \mathrm{x}_{4}+$ $0.063 \mathrm{x}_{5}+0.118 \mathrm{x}_{6}-0.090 \mathrm{x}_{7}-0.090 \mathrm{x}_{8}+0.104 \mathrm{x}_{9}+$ $0.007 \mathrm{x}_{10}$

$\dot{\mathbf{X}}_{\mathrm{TCTP}}=(-1,1,1,1,1,1,-1,-1,1,1)$

The above results show that for the TCTP decision maker can plan activities 1,7 and 8 to make use of lower limits of available results, while activities 2,3 , 4,5,6,9 and 10 should also be allocated the upper limits of available resources. The resources to be allocated therefore for each corresponding activity in increasing order are:
$\dot{\mathrm{X}}_{\mathrm{TCTP}}=(100,000,1000,000,250000,180,000$, $280,000,300,000,100,000,150,000,60,000,60,000)$ $=\mathrm{N} 2,480,000.00$

$\mathrm{P}_{\mathrm{TRTP}}=\mathrm{p}(3<\mathrm{T}<5,30<\mathrm{R}<50)$ $=0.604+0.063 \mathrm{x}_{1}-0.146 \mathrm{x}_{2}+0.062 \mathrm{x}_{3}-0.021 \mathrm{x}_{4}$

$+0.021 \mathrm{x}_{5}+0.104 \mathrm{x}_{6}-0.104 \mathrm{x}_{7}+0.021 \mathrm{x}_{8}-0.021 \mathrm{x}_{9}+$ $0.063 \mathrm{x}_{10}$

$\dot{\mathbf{X}}_{\mathrm{TRTP}}=(1,-1,1,-1,1,1,-1,1,-1,1)$.

Similarly, the decision variables for the TRTP indicate that activities $1,3,5,6,7$ and 10 should be planned within the upper limits of available resources while activities 2,4,9 and 10 should be planned using lower limits for optimum performance. Hence,

$\dot{\mathbf{X}}_{\mathrm{TRTP}}=(120,000,800,000,250,000,120000,280000$, $300000,100000,165000,80000,60000)=\mathbf{N} 2$, $275,000.00$ 
$\mathrm{P}_{\text {CRTP }}=\mathrm{p}(50<\mathrm{C}<150,30<\mathrm{R}<50)$

$=0.750+0.083 \mathrm{x}_{1}+0.083 \mathrm{x}_{2}+0.208 \mathrm{x}_{3}-0.000 \mathrm{x}_{4}-$ $0.042 \mathrm{x}_{5}+0.125 \mathrm{x}_{6}-0.125 \mathrm{x}_{7}-0.000 \mathrm{x}_{8}+0.042 \mathrm{x}_{9}-$ $0.000 \mathrm{x}_{10}$

$$
\dot{\mathrm{X}}_{\mathrm{CRTP}}=(1,1,1,-1,-1,1,-1,-1,1,-1)
$$

The decision variables for the CRTP indicate that activities 1,2,3,4 and 9 should be allocated the upper limits of available resources while activities 4, 5, 7, 8 and 10 should be assigned the lower limits of available resources for optimum performance. This means that: $\dot{\mathrm{X}}_{\mathrm{CRTP}}=(120,000,1,000,000,250,000,120,000$, $230,000,300,000,100,000,150,000,120,000,50,000$ ) $=\mathrm{N} 2,440,000.00$

$\mathrm{P}_{\mathrm{TCRTP}}=\mathrm{p}(3<\mathrm{T}<5,50<\mathrm{C}<120,30<\mathrm{R}<50)$

$=0.462+0.0241 \mathrm{x}_{1}-0.0346 \mathrm{x}_{2}+0.133 \mathrm{x}_{3}+0.064 \mathrm{x}_{4}+$ $0.024 \mathrm{x}_{5}+0.163 \mathrm{x}_{6}-0.145 \mathrm{x}_{7}-0.061 \mathrm{x}_{8}+0.018 \mathrm{x}_{9}+$ $0.103 \mathrm{x}_{10}$

$$
\dot{\mathrm{X}}_{\mathrm{TCRTP}}=(1,-1,1,1,-1,1,-1,1,1,-1) .
$$

Finally, the regression equation for the TCRTP shown above indicate that activities A, C,D, F, H, and I should be allocated to the upper limits of available resources while activities B,E, G and J should be allocated the lower limits of available resources. Hence:

$\dot{\mathrm{X}}_{\text {TCRTP }}=(120000,800000,250000$, $180000,230000,300000,160000,165,000,120,000$, $50000)=\mathrm{N} 2,375,000$

\subsection{Comparison of RSM to MOGA}

Furthermore, the performance of the models is validated by using a multiobjective genetic algorithm (MOGA) to solve the above model in MATLAB software version (R2009a). The parameters for the algorithm are presented in Table 7 below:

Table7: Parameter settings

\begin{tabular}{clc}
\hline S/N & PARAMETERS & VALUES \\
\hline 1 & Population size & 200 \\
2 & Generations & 200 \\
3 & Selection & Tournament selection \\
3 & Crossover & Single point crossover \\
4 & Crossover fraction & 0.7 \\
5 & Mutation Function & Adaptable feasible \\
\hline
\end{tabular}

The GA was implemented based on the objective functions and constraints in equations (1) - (10) above. The results for the TCRTP using GA show that the total time, cost, and risk values are 25, 2,334,5946 and 26.77 respectively.

\section{DISCUSSION}

The results above were used to show that RSM methodologies can be used to assign appropriate resource levels to each activity. The total amount of resources to obtain optimum values for the different trade-off values vary from one to the other. The total amount of resources required for the different tradeoff models are $\mathrm{N} 1,304,000.00, \mathrm{~N} 1,290,000.00$, $\mathrm{N} 1,284,000.00$ and $\mathrm{N} 1,073,000.00$ for TCTP, TRTP,
CRTP, and TCRTP respectively. It should be noted that decision variables for the TRTP will require the least number of resources while the optimal decision variables for the TCTP will require the highest amount of resources. The above results obtained from the optimization models will assist project managers in taking appropriate decisions on the amount of resources required in a project to determine the time, cost and risks required in the implementation of the project. Interestingly, this study has demonstrated novel trade-off models which have not been studied previously and need further investigation. The novel models include the TRTP and CRTP. The implication of the above results is that there is a close relationship between the project risk and the duration as well as the resources. The upper limits of the resources are required in most cases to obtain optimal trade-off values.

The RSM showed good performance when compared with the performance of MOGA. In addition, it provided several options to determine the performance of the different trade-offs.

\section{CONCLUSION}

In this study, the Time-Cost-Risk trade-off of the different project objectives for X-ray machine installation procedure was implemented using response surface methodology. The purpose of the TCRTP in project management was enunciated and its application to installation procedures of an X-ray machine demonstrated. Trade-off models for TRTP, CRTP were developed as contribution to the sparse literature on the subject matter.

\section{REFERENCES}

[1] British Standards 2002, Guide to Project management. No. BS6079-1:2002. BSI.

[2] Demeulemeester, E., Herroelen, W.S. and Elmaghraby, S.E. 1996, 'Optimal procedures for the discrete time/cost trade-off problem in project networks', European Journal of Operational Research, 88(1): 50-68.

[3] Hazir, O. Haouari M. and Erel E. 2010, "Discrete time/cost trade-off problem: A decomposition-based solution algorithm for the budget version", Computers and Operations Research 37 (2010) 649 -655 .

[4] Azaron, A. Perkgoz C. and Sakawa, M. 2005, "A genetic algorithm approach for time cost trade off in PERT networks", Applied mathematics and computation, 168:1317-1339.

[5] De P. Dunne E.J. Ghosh J.B and Wells C.E 1997. "Complexity of the Discrete Time-Cost Trade- off Problem for Project Networks", Operations Research Journal, 45(2):302

[6] Feng C.W, Liu L. and Burns S.A. 1997, " Using genetic algorithms to solve construction time cost trade-off 
problems" Journal of Computing in Civil Engineering, 11(3):184-189.

[7] Akpan E.O.P. 2012, "Time/Cost Trade-off Analysis: The Missing Link" Prime Journal of Engineering and Research 1(2):26-31

[8] Gutjahr W.J. Strauss C. Wagner E. 2000, “A stochastic branch-and-bound approach to activity crashing in project management. INFORMS J Computing 12(2):125-135.

[9] Golenko-Ginzberg D. and Gonik A. 1998, "A heuristic for network project scheduling with random activity durations depending on the resource allocation". International Journal of Production Economics 55:149-162.

[10] Vrat, P. and C. Kriengkrairut, 1986. "A goal programming model for project crashing with piecewise linear time-cost trade-off. Engineering Costs and Production Economics", 10(1):161172.

[11] Foldes S, Soumis F.1993, "PERT and crashing revisited: mathematical generalization. European Journal of Operations Research 64:286-294.

[12] Son J. Hong, T., and S. Lee 2013. "A Mixed (Continuous + Discrete) Time-Cost Trade-Off Model Considering Four Different Relationships with Lag Time" KSCE Journal of Civil Engineering (2013) 17(2):281-291.

[13] Burns S.A. Liu L. Feng C. 1996, “The LP/IP hybrid method for construction time/cost trade-off analysis". Construction Management and Economics. 14(3): 265-276.

[14] Iranmanesh H. Sikandari M.R. and Allahverdiloo M. 2008, "Finding pareto optimal front for multimode time, cost quality tradeoff in project scheduling" World academy of Science ,Engineering and Technology, 40:346-350.

[15] Lakshminarayanan S., Gaurav A. and Arun C. 2011, "Time-Cost-Risk Trade Off Using Ant Colony Optimization" Journal of Construction in Developing Countries.

[16] Gambatese, J., and Hinze, J. 1998, "Addressing construction worker safety in the design phase: Designing for construction worker safety". Automation in Construction, 8(6), pp.643-649.

[17] McVeigh, H., and Hoey, V. 2006,"Putting Safety First During Integration: Mergers \& Acquisitions", The Dealer Maker Journal, 41(11), pp.54-59.

[18] Litske, H. 1997, "A New Forward Looking Economic Incentive Model to Improve Health and Safety" Safety Science Monitor, 1(1), Article4, pp.3.
[19] Einarsson, S. 1998, "The relationship between construction contractors and their clients in petrochemical and related industries". Safety Science Monitor, 2(2), Article5, pp.19.

[20] Dyersburg, J., and Mikkelsen, K. L. 2003,"Evaluation of an accident investigation tool using a safety perception maturity scales". Safety Science Monitor, 7(1), Article II-1; 9pgs.

[21] Hall E.J. Brenner D.J. 2008. "Cancer risks from diagnostic radiology". British Journal of Radiology I81 (965): 362-78.

[22] Roobottom CA, Mitchell G, and Morgan-Hughes G. 2010, "Radiation-reduction strategies in cardiac computed tomographic angiography". Clinical Radiology 65 (11): 859-67.

[23] Berrington, A; Darby, A; Darby, S (2004). "Risk of cancer from diagnostic X-rays: estimates for the UK and 14 other countries". Lancet363 (9406): 345351.

[24 Health and Safety at Work etc. Act 1974: "Risk management: ALARP at a glance". London: Health and Safety Executive. Retrieved 13 February 2013.

[25] Chiao C.H. Hamada M. 2001, Analyzing experiments with correlated multiple responses. J Qual Technology 33(4):451-465

[26] Salmasnia A., Mokhtari H. and Abadi N.K. 2011, “A robust scheduling of projects with time, cost, and quality considerations" International Journal of Advanced manufacturing Technology.24:9-10.

[27] Box G.E.; Hunter, J.S.; Hunter, W.G. 2005. Statistics for Experimenters: Design, Innovation, and Discovery, 2nd Edition. Wiley.

[28 Mbanugo C.E., Agunwamba J.C and Eke M.N. "Risk Analysis Applied In Oil Exploration and Production" Nigerian Journal of Technology. 30(2): 73 - 79.

[29]Oladeinde M.H. and Oladeinde C.A. 2014. “An Investigation into the Decision Maker's Risk Attitude Index Ranking Technique for Fuzzy Critical Path Analysis" Nigerian Journal of Technology 33(3):345 -350 .

[30] Graves, R. 2000. “Qualitative Risk Assessment." PM Network 14(10): 61-66.

[31] Saputra Y.A. and Ladamay O.S.A. 2011, "Project Reliability: Probability Of A Project Meets Its QualityCost-Time Target Under Uncertainty" International Journal of Electronic Business Management, 9(3): 220-230.

[32]Montgomery D.C. and Runger G.C. 2003, Applied Statistics and Probability for Engineers $3^{\text {rd }}$ edition, John Wiley and Sons, USA. 